\title{
AC 2012-5108: DESIGN OF EXPERIMENTS MODELING OF A HEAT TUNNEL
}

\section{Dr. Lash B. Mapa, Purdue University, Calumet}

Lash Mapa is a professor in industrial/mechanical engineering technology at Purdue University, Calumet (PUC). His undergraduate and graduate degrees are in chemical engineering. He has several years' experience as a Chemical Engineer, Process, and Project Manager with European and U.S. manufacturing organizations. Currently, he is involved in the M.S. Technology program at PUC and has managed more than 30 Lean Six Sigma projects with manufacturing, service industry, and educational institutions.

\section{Mr. Avanish Reddy Vancha, Purdue University, Calumet}

Avanish Reddy Vancha is a master's student in industrial engineering technology at Purdue University, Calumet (PUC). His undergraduate degree is in electronics and communications engineering. He is a Graduate Assistant at Purdue University teaching the undergraduate course Statistical Process Control and his research areas are design of experiments (DOE) and radio frequency identification (RFID) technology. $\mathrm{He}$ is a certified Six Sigma Green Belt by American Society for Quality. 


\begin{abstract}
There are many factors that contribute to heat losses in tunnels used in processing and this is an attempt to understand the factors that are significant in reducing the heat losses, with the long term goal of making design improvements to increase the efficiency of the equipment to provide value to the customer. Retaining the heat in a process heat tunnel is important for several reasons. Temperature settings, safety, environmental pollution and energy conservation are the major ones. As energy prices continue to escalate, economic benefits of energy conservation should be examined. State and federal teams are now pushing standards for ovens to gain energy efficiency; but many manufacturers feel that the upgrading of heat tunnel energy efficiency would affect their bottom line adversely. Heat tunnels present further challenges as they all incorporate openings to allow the conveyor and products to enter and exit the oven. These 'product apertures' require measures to reduce the escape of heat from the tunnel and the consequential increase in operating costs. The most common method in fast production lines is the use of curtains. The present study was performed to understand the direction that a designer should concentrate to maximize the process settings such as curtain design, temperature, conveyor speed, heat generation levels and insulation thickness. This was achieved by constructing a Design of Experiments (DOE) model to investigate the factors that affect heat losses at high (+) and low (-) levels.
\end{abstract}




\section{Introduction}

Increasing the standards of quality and improving the productivity is every company's goal. Design of experiments $(D O E)$ is a scientific and statistical way of improving system and process performance. $D O E$ is an efficient procedure for planning experiments so that the data obtained can be analyzed to yield valid and objective conclusions. Many industries conduct surveys and with the passive observations yields conclusions in terms of process improvement, but $D O E$ aims at the understanding of the relationship among the input variables and the output variables in a process and ends with an improved model of relationship between the variables (figure 1).

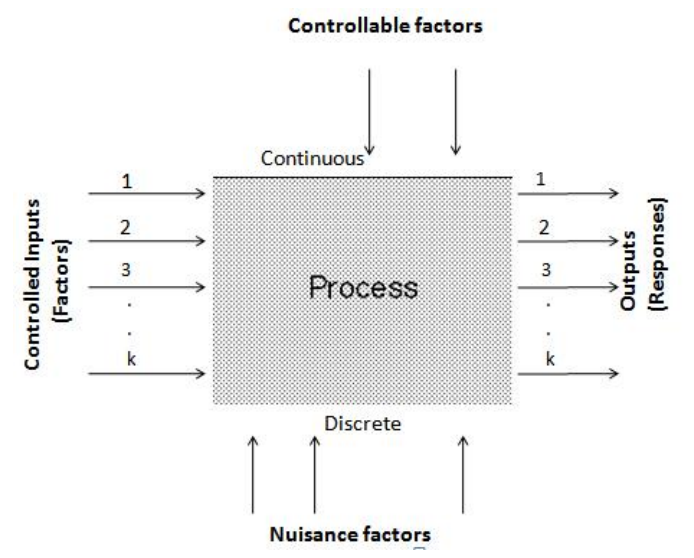

Figure1 Schematic Model of a Process

The foundation for the modern statistical experimental design was led by the pioneering work of Sir Ronald A. Fisher in $1920{ }^{1}{ }^{1}$. Fisher's systematic study introduced statistical thinking and principles into designing experimental investigations. Initially, the primary application of DOE was in agriculture and it made a significant impact on industrial applications because of the robustness of the response variable and quick learning of crucial information by experimenter with a small number of experiments.

The use of designed experiments in industry gradually developed in the 1950s with progress both in the West and in Japan ${ }^{2}$. Design of experiments is been used in simulations for decision making in semi-conductor industry. The benefits of the design of experiments in simulation include the possibility of improving the performance on the simulation process, avoiding the trial-and-error techniques to seek solutions.

Global packaging industry growth rates vary across the types of packaging. The growth rate of beverages packaging industry is $3.2 \%$, whereas it is $5 \%$ for health care products. Various market reports establish the fact that the domestic packaging market shares $29 \%$ of the global market ${ }^{3}$. Sustainability is becoming a major issue for many packaging companies of which energy is one of them. Most of the companies have achieved success in reducing energy usage by the machines in past years. Modern furnaces have, for instance, contributed to this reduction, as has adhering to legal emission limits.

Industrial packaging ovens consume a large amount of energy to operate and there is always scope to conserve energy. There are many factors that contribute to heat losses in ovens, and this 
paper exposes the factors that are significant in reducing the heat losses, with the long term goal of making design improvements to increase the energy utilization of the ovens.

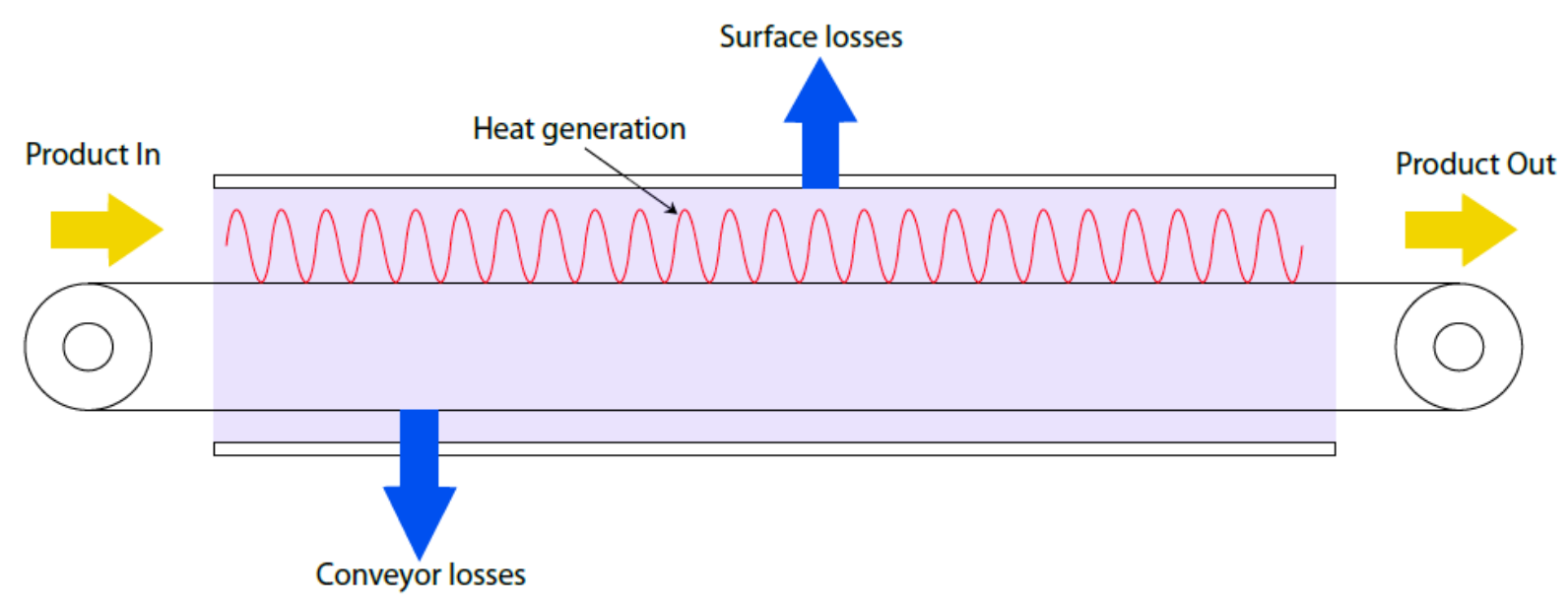

Figure 2 Model of a common conveyor oven

A typical model of an oven used in packaging industry to heat shrink packages heat is shown in figure 2. The process variables that contributes to heat losses from a conveyor type oven are, losses from the inlet and outlet as products enter and leave the oven, surface losses from the exterior of the oven and heat absorbed by the conveyor and the product. In re-designing such ovens to minimize heat losses it is important to identify which factor/s contributes to energy losses. The process variables which have been considered as factors and taken into consideration in DOE are the design of curtains that helps to minimize heat losses at the entry and exit ports, the speed of the conveyor belt, the speed of the blower that introduces hot air into the oven chamber and the insulation material around the oven. In this paper $2^{\mathrm{k}}$ factorial design is used to analyze the data to identify main effects and the interaction effects of the factors that were investigated $^{5}$. Data was analyzed using SAS (Statistical Analysis software) Statistical software ${ }^{6}$ that helped to identify the factors that has significance.

\section{Equipment}

A commercial oven using electrical energy was used to perform the DOE. The size of the oven is $5 \mathrm{ft}$. long with the tunnel opening of 34 in. wide and $17^{\circ}$ high. This type of oven is a basic model used to shrink wrap products that are packed on cardboard tray. The oven has two conveyor belts, one to feed the product into the oven and the other that conveys the product through the oven. It has a standard hot air blower and the speed of the blower settings varies from $30 \mathrm{~Hz}$ to $70 \mathrm{~Hz}$. A shrink wrap film of 2 mil x 18" wide was used in the experiment. The entry and the exit ports were covered with single layered overlapping curtains usually referred as flaps; each flap is 6in. wide and 17in. high. The oven control panel allows the operator to vary the conveyor belt speed and the blower speed and has the capability to display the heater 'ontime'. The heater 'on-time' is the length of time the heating element is turned on and is the key output reading from the experiments. A beverage pack containing twelve items was used as the product to be shrink wrapped. The speed of the conveyor belt could be varied from 22-77 ft. per 
min. Operating the conveyor belt too fast or too slow leads to unacceptable packaging of the product.

\section{Methodology}

Experiments were performed by processing beverage trays containing twelve items through the oven. The packs are shrink wrapped, and the heater 'on-time' was recorded. From discussions with the designers of the oven, the process variables that are contributing to the heat losses was identified as flap design, speed of the conveyor belt, blower speed, and insulation.

As there are four factors, two at each level a $2^{4}$ factorial design was used ${ }^{3}$. It helps in analyzing the data obtained to identify major factors and interaction between the factors at the levels tested. Nuisance factors were minimized using the same batch of shrink wrap material and performing the experiment in one day. For comparison purposes and to create baseline information, additional data was gathered.

A baseline data for heater on-time was collected for 10 minutes of trial run of the oven without the product being sent. To simulate a typical production run a set of 15 beverage packs (each pack contains twelve items) were fed at 10 second intervals for a period of 5 minutes. Each experimental run was duplicated for another 5 minutes to eliminate the errors generated in collection of data. Table 1 presents the factors and levels and table 2 the experimental layout used for this experiment to minimize heating time.

Table 1 Factors and levels

\begin{tabular}{|l|c|c|c|}
\hline \multicolumn{1}{|c|}{ Factors } & Designation & Low(-) & High(+) \\
\hline Flap design & A & Std. single layer & 4 " double layer \\
\hline Speed of conveyor belt & B & $35 \mathrm{~Hz}$. & $50 \mathrm{~Hz}$. \\
\hline Blower Speed & C & $40 \mathrm{~Hz}$. & $60 \mathrm{~Hz}$. \\
\hline Insulation $^{*}$ (additional) & D & No & Yes \\
\hline
\end{tabular}

* The oven has built-in insulation 
Table 2.0 Experimental layout with response values

\begin{tabular}{|c|c|c|c|c|c|c|}
\hline Std order. & A & B & $\mathrm{C}$ & $\mathrm{D}$ & Time (s) & Time ( sec.) \\
\hline 1 & - & - & - & - & 2:09 & 129 \\
\hline 2 & + & - & - & - & $1: 53$ & 113 \\
\hline 3 & - & + & - & - & $2: 20$ & 140 \\
\hline 4 & + & + & - & - & $1: 53$ & 113 \\
\hline 5 & - & - & + & - & $2: 55$ & 175 \\
\hline 6 & + & - & + & - & $2: 25$ & 145 \\
\hline 7 & - & + & + & - & $2: 59$ & 179 \\
\hline 8 & + & + & + & - & $2: 22$ & 142 \\
\hline 9 & - & - & - & + & $2: 20$ & 140 \\
\hline 10 & + & - & - & + & $2: 00$ & 120 \\
\hline 11 & - & + & - & + & $2: 26$ & 146 \\
\hline 12 & + & + & - & + & 2:02 & 122 \\
\hline 13 & - & - & + & + & $2: 51$ & 171 \\
\hline 14 & + & - & + & + & $2: 24$ & 144 \\
\hline 15 & - & + & + & + & $3: 00$ & 180 \\
\hline 16 & + & + & + & + & $2: 22$ & 142 \\
\hline 17 & - & - & - & - & $2: 10$ & 130 \\
\hline 18 & + & - & - & - & $1: 51$ & 111 \\
\hline 19 & - & + & - & - & $2: 15$ & 135 \\
\hline 20 & + & + & - & - & $1: 52$ & 112 \\
\hline 21 & - & - & + & - & 3:08 & 188 \\
\hline 22 & + & - & + & - & $2: 23$ & 143 \\
\hline 23 & - & + & + & - & $2: 59$ & 179 \\
\hline 24 & + & + & + & - & $2: 29$ & 149 \\
\hline 25 & - & - & - & + & $2: 22$ & 142 \\
\hline 26 & + & - & - & + & $2: 01$ & 121 \\
\hline 27 & - & + & - & + & $2: 11$ & 131 \\
\hline 28 & + & + & - & + & 2:05 & 125 \\
\hline 29 & - & - & + & + & 3:00 & 180 \\
\hline 30 & + & - & + & + & $2: 23$ & 143 \\
\hline 31 & - & + & + & + & $3: 01$ & 181 \\
\hline 32 & + & + & + & + & $2: 22$ & 142 \\
\hline
\end{tabular}

\section{Data Analysis}

The factorial plot of the subject data is displayed in table 2. In this figure -1 represents the low level and 1 represents the high level of each factor. Since the objective of the study is to minimize the "heater-on" time, it is of interest to identify the level of each factors so that it will minimize the time. From the factorial plots it can be observed that the minimum time is displayed with shorter bars. 


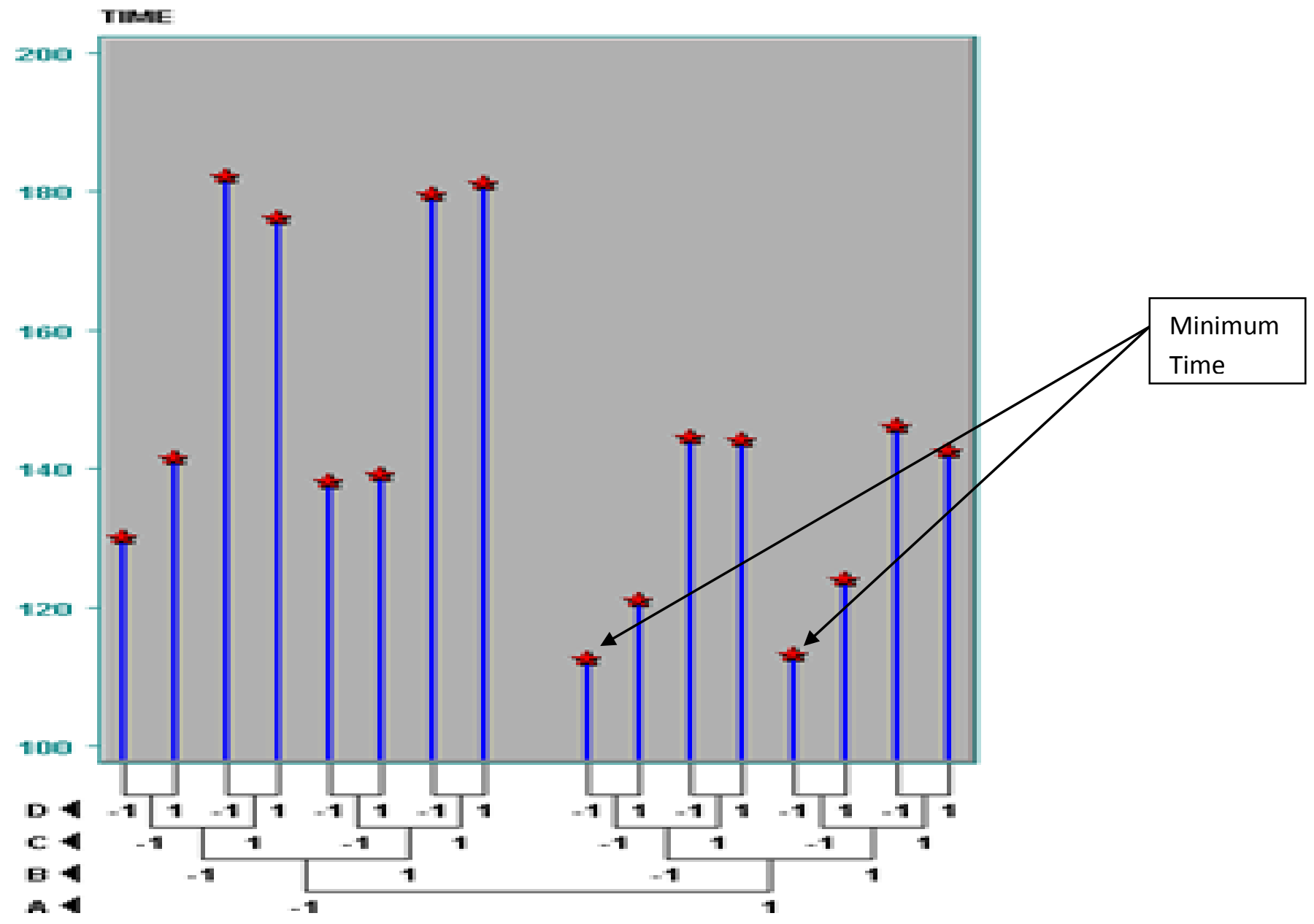

Figure 3 Factorial plots

Since there are more than two factors of interest, in order to quantify the effects of each of the main factors and their first order interactions analysis of variance (ANOVA) was performed. It is noted from the ANOVA table (table 3.0) that the main effect of A (flap design) and C (blower speed) are highly significant because both have very small $p$-value. The p-value helps to determine the significance level of the factors and their interactions. The AC interaction is also highly significant meaning that there is a strong relationship between A and C. It is evident that the variation is primarily driven by the factors $\mathrm{A}$ and $\mathrm{C}$. But the effect of $\mathrm{D}$ cannot be ignored as it shows interaction with the factor $\mathrm{C}$ as well as it is significant for any level greater than 0.0649 . 
Table 3 ANOVA Table

\begin{tabular}{|l|c|r|r|l|l|}
\hline Source & DF & SS & MS & F-value & p-value \\
\hline $\mathrm{A}$ & $\mathbf{1}$ & $\mathbf{6 0 2 2 . 5}$ & $\mathbf{6 0 2 2 . 5}$ & $\mathbf{3 3 0 . 9 4 2 9}$ & $\mathbf{0 . 0 0 0 1}$ \\
\hline $\mathrm{B}$ & 1 & 16.5 & 16.5 & 0.9067 & 0.3514 \\
\hline $\mathrm{C}$ & $\mathbf{1}$ & $\mathbf{9 5 5 6 . 5}$ & $\mathbf{9 5 5 6 . 5}$ & $\mathbf{5 2 5 . 1 4 0 1}$ & $\mathbf{0 . 0 0 0 1}$ \\
\hline $\mathrm{D}$ & 1 & 69.0 & 69.0 & 3.7916 & 0.0649 \\
\hline $\mathrm{AB}$ & 1 & 2.5 & 2.5 & 0.1374 & 0.7129 \\
\hline $\mathrm{AC}$ & $\mathbf{1}$ & $\mathbf{5 0 4 . 0}$ & $\mathbf{5 0 4 . 0}$ & $\mathbf{2 7 . 6 9 5 4}$ & $\mathbf{0 . 0 0 0 1}$ \\
\hline $\mathrm{AD}$ & 1 & 7.0 & 7.0 & 0.3847 & 0.5409 \\
\hline $\mathrm{BC}$ & 1 & 5.3 & 5.3 & 0.2912 & 0.5957 \\
\hline $\mathrm{BD}$ & 1 & 1.5 & 1.5 & 0.0824 & 0.7746 \\
\hline CD & $\mathbf{1}$ & $\mathbf{2 0 5 . 0}$ & $\mathbf{2 0 5 . 0}$ & $\mathbf{1 1 . 2 6 5 0}$ & $\mathbf{0 . 0 0 2 9}$ \\
\hline Error & 21 & 382.16 & 18.198 & & \\
(LOF) & 5 & 94.66 & 18.932 & & \\
(Pure) & 16 & 287.50 & 287.5 & & \\
\hline
\end{tabular}

Table 4.0 Summary

\begin{tabular}{|l|l|l|l|l|}
\hline Mean & R-square & Adj. R-square & RMSE & CV \\
\hline 144.1563 & $97.72 \%$ & $96.64 \%$ & 4.265 & 2.96 \\
\hline
\end{tabular}

The Statistical Analysis Software (SAS) output of the parameter estimates and the significance of each of the main factors and the first order interaction are given in table 2.0.

Parameter estimates

\begin{tabular}{lllll|} 
Effect & Estimate & Std Error & \multicolumn{1}{l}{ R Ratio } & P Value \\
\hline $\mathrm{A}$ & -27.438 & 1.5082 & -18.192 & $<.0001$ \\
\hline $\mathrm{B}$ & 1.4375 & 1.5082 & 0.95311 & 0.3514 \\
\hline $\mathrm{C}$ & 34.563 & 1.5082 & 22.916 & $<.0001$ \\
\hline $\mathrm{D}$ & 2.9375 & 1.5082 & 1.9477 & 0.0649 \\
$\mathrm{~A}^{\star} \mathrm{B}$ & -0.5625 & 1.5082 & -0.37296 & 0.7129 \\
\hline $\mathrm{A}^{\star} \mathrm{C}$ & -7.9375 & 1.5082 & -5.2628 & $<.0001$ \\
\hline $\mathrm{A}^{\star} \mathrm{D}$ & 0.9375 & 1.5082 & 0.62159 & 0.5409 \\
$\mathrm{~B}{ }^{\star} \mathrm{C}$ & -0.8125 & 1.5082 & -0.53871 & 0.5957 \\
$\mathrm{~B}{ }^{\star} \mathrm{D}$ & -0.4375 & 1.5082 & -0.29008 & 0.7746 \\
\hline $\mathrm{C}{ }^{\star} \mathrm{D}$ & -5.0625 & 1.5082 & -3.3566 & 0.0030 \\
\hline
\end{tabular}


A regression model approach was used to illustrate the relationship between the response and process parameters. The coded variables are shown below.

$$
x_{1}=\frac{A-\left(A_{\text {Low }}+A_{\text {High }}\right) / 2}{\left(A_{\text {High }}-A_{\text {Low }}\right) / 2} \quad x_{2}=\frac{B-\left(B_{\text {Low }}+B_{\text {High }}\right) / 2}{\left(B_{\text {High }}-B_{\text {Low }}\right) / 2} \quad x_{3}=\frac{C-\left(C_{\text {Low }}+C_{H i g h}\right) / 2}{\left(C_{\text {High }}-C_{\text {Low }}\right) / 2} \quad x_{4}=\frac{D-\left(D_{\text {Low }}+D_{\text {High }}\right) / 2}{\left(D_{\text {High }}-D_{\text {Low }}\right) / 2}
$$

The regression model for predicting the time (heater on) $\hat{y}$ (in seconds) is given by

$$
\begin{gathered}
\hat{y}=144.16-13.72 x_{1}+0.72 x_{2}+17.28 x_{3}+1.47 x_{4}-0.28 x_{1} x_{2}-3.97 x_{1} x_{3} \\
+0.47 x_{1} x_{4}-0.41 x_{2} x_{3}-0.22 x_{2} x_{4}-2.53 x_{3} x_{4}
\end{gathered}
$$

The regression model with only the significant factors the predicted heater on-time is:

$$
\hat{y}=144.16-13.719 x_{1}+17.281 x_{3}-3.9688 x_{1} x_{3}-2.5313 x_{3} x_{4}
$$

Also note that the coefficient of determination (R-square) of the model is 0.9711 indicating that about 97 percent of the variability in the time taken is explained by the main factors and first order interaction of the factors.

\section{Model Adequacy Checking}

While creating a regression model we assume that the errors are normally and independently distributed with mean zero and constant but unknown variance. It is quite important that these assumptions are verified in order to make decisions of the applicability of the model. Violations of the assumptions and the adequacy of the model can be checked using the residuals which are obtained by calculating the difference between the observed and expected. If the model is adequate, the residuals should be structureless which means it should not contain an obvious pattern. We may use the normal probability plot of the residuals to verify the normality assumptions. If the underlying error distribution is normal, this plot will resemble a straight line. Figure 2 and Figure 3 displays the residual plots and the normality plots. It can be seen that even though it doesn't fully support the model assumptions but is not severe enough to have a dramatic impact on the analysis and conclusions. 


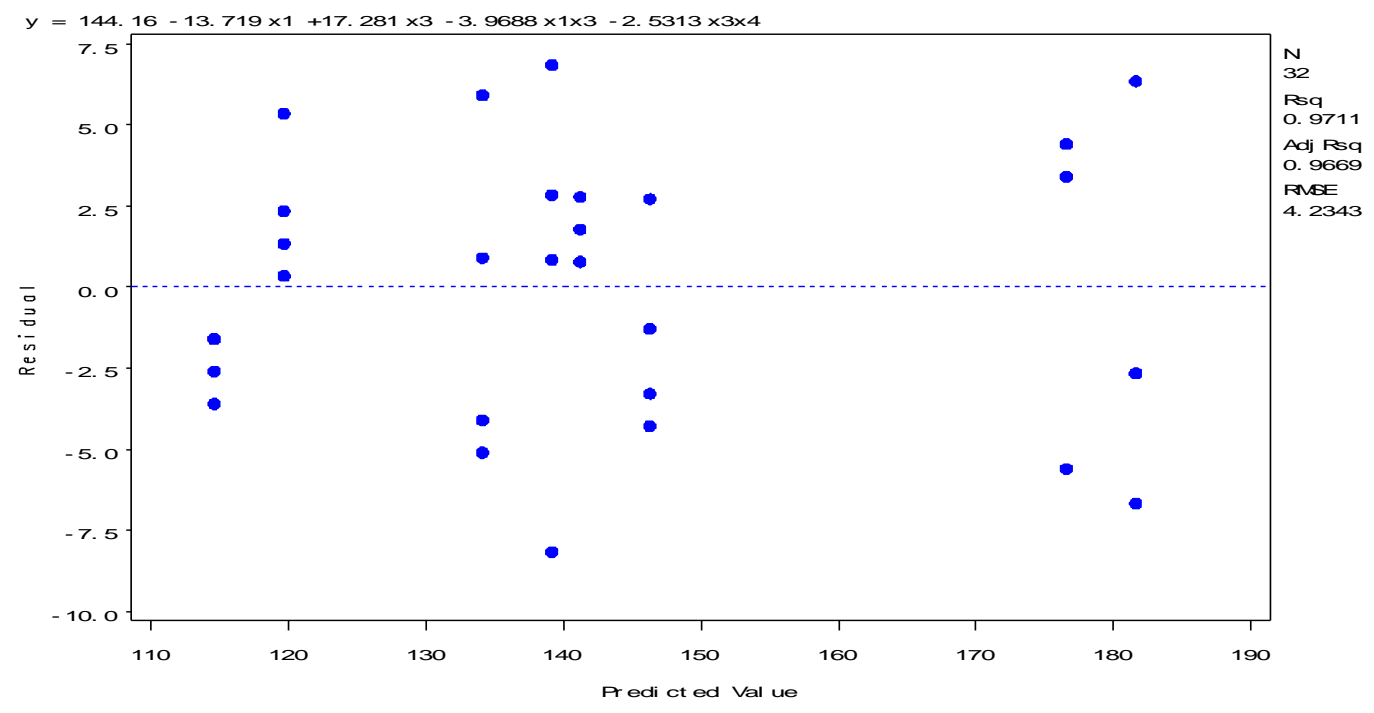

\section{Conclusions}

The DOE methodology assisted the designers to investigate possible combinations of the levels of the factors in the experiment. Varying the key factors identified by the designers, the flap design, conveyor belt speed, blower speed and extra insulation it has been concluded that:

a) The most significant factors are the flap design and the blower speed

b) The effect of conveyor belt speed and presence of extra insulation are not significant for the desired level of significance of 0.05 .

c) The effect of insulation cannot be ignored if the level of significance is changed

d) The interaction between flap design and blower speed as well as the blower speed and the insulation are also significant.

e) The regression model with only the significant factors the predicted heater on-time is: $\hat{y}=144.16-13.719 x_{1}+17.281 x_{3}-3.9688 x_{1} x_{3}-2.5313 x_{3} x_{4}$

\section{Bibliography}

1. F. Yates, Biometrics, Vol. 20, No. 2, Jun., 1964, p.307-321

2. Shirley Y. Coleman and D.J.Stewardson, Pro-ENBIS Workshop for Business and Management, DEINDE Conference, Sardinia 29-30 May 2003, Designed experiments within a problem solving framework with examples in management and the service sector.

3. Energy-saving packaging - for sustainable industry, interpack magazine, interpack Processing \& Packaging, Dusseldorf, Germany, May 2011 website

4. Douglas C. Montgomery, Design and Analysis of Experiments, $7^{\text {th }}$ edition, P.227, Wiley publications.

5. Jiju Anthony, Design of Experiments for Engineers and Scientists, P.22, Elsevier Ltd., 2009.

6. SAS Institute Inc., SAS Online Doc 9.1.3. Cary, NC-SAS Institute Inc., 2004 